Volume 10, No.2, March - April 2021

International Journal of Advanced Trends in Computer Science and Engineering

Available Online at http://www.warse.org/IJATCSE/static/pdf/file/ijatcse1281022021.pdf

https://doi.org/10.30534/ijatcse/2021/1281022021

\title{
Intelligent Air Pollution Monitoring System for Smart Cities Using IoT and Machine Learning
}

\author{
Irshad Ali Wassan ${ }^{1}$, Mir Sajjad Hussain Talpur ${ }^{1}$, Ammar Oad $^{2}$, Raheel Sarwar ${ }^{1}$, Abida Luhrani ${ }^{1}$, Shakir \\ Hussain Talpur ${ }^{1}$, Fauzia Talpur ${ }^{3}$, Taha Nuzhat ${ }^{1}$, Aneel Oad $^{4}$ \\ ${ }^{1}$ Information Technology Centre, Sindh Agriculture University Tandojam, Sindh, Pakistan, \\ mirsajjadhussain@sau.edu.pk \\ ${ }^{2}$ Faculty of Information Engineering, Shaoyang University, Shaoyang 422000, China, \\ ammar_2k309@yahoo.com \\ ${ }^{3}$ University Sindh Laar Campus Badin, fozia.g.talpur.gmail.com \\ ${ }^{4}$ Central South University, China, oad_aneel@yahoo.com
}

\begin{abstract}
Today, almost everything is going under automation. Air pollution has become one of the major crises across the globe. According to the report of the World Health Organization (WHO), around 580,000 people died due to air pollution. This document deals with the effective monitoring of air pollution systems. The proposed technique uses machine learning algorithms for the intelligent monitoring of air pollution. The concept of the Internet of Things (IoT) is implemented in the system to make it more reliable and accessible from anywhere throughout the world. ESP32 is used as a microprocessor for decision making purposes. The system uses Arduino software to build an algorithm. The DHT11 module is used to sense the humidity as well as temperature. MQ-2, MQ-7 and MQ-135 are used for sensing the level of methane, carbon monoxide and for measuring air quality, respectively. A buzzer is used to identify any unusual condition. Our work considers pollution caused by vehicles and provides an in-the-moment solution that does not directly monitor pollution levels, as well as control measures for reducing traffic in extremely polluted areas. This system will undoubtedly be on humans' behalf in such a way that a smart city will have much less time for spending, and there will undoubtedly be other industries, and the air will undoubtedly be extra polluted, and this device will undoubtedly allow people to understand how safe the air is.
\end{abstract}

Key words: IoT, Smart Home, Paralyzed Patients Sensors

\section{INTRODUCTION}

The World Health Organization (WHO) updated previous estimates of air pollution-related mortality in 2018, more than doubling the previous estimates. 1st Surprisingly, air pollution is now believed to be the cause of one out of every eight deaths worldwide, rendering it the world's single most serious environmental health hazard. 1 and 2 These revisions show how difficult it is to model the relationship between standard measurement methods and personal exposure, as well as the relationship between exposure and health. Failure to recognize and comprehend these connections will weaken and obfuscate the global health threats that the world faces [1-9]. This section will primarily cover the history and basics of air pollution monitoring in order to keep the atmosphere as safe as possible. Furthermore, the significance of the analysis, the inspiration for the research, and the goals will all be discussed. At the end of this section, the thesis's scope will be discussed. Understanding everyday pollution exposure- and making informed changes to reduce it- might literally extend the lives of millions of people living in toxically contaminated cities around the world. Over the last few years, the number of low-cost consumer devices has exploded to meet this demand; however, none have proved to be effective in real-world situations.

Air pollution is one of the most serious problems that humans face around the world. If not treated correctly and promptly, it can lead to a variety of serious diseases. As humans, we have a primary duty to protect our world from all harmful and inappropriate chemicals. In the real world, industrialization is accelerating on a daily basis. As technology is implemented to perform various tasks associated either directly or indirectly with human life, more and more factories are being built. The majority of these factories or industries release hazardous gases or chemicals into the atmosphere. It induces abrupt atmospheric changes as well as air pollution, all of which are harmful to living beings. People who used to work in these industries or factories are in fact at greater risk than those who do not live near industrial zones. Despite the complexities behind sparse air quality measurement and individual health, there is a plethora of evidence linking small particulate matter and other pollutants to serious negative health. effects. Air pollution has unfavorable impacts on the lives of animals, plants and other living things. It is the major issue that is being continuously faced by the entire world. 
Utilizing natural assets at a rate higher than the ability of nature for their re-establishment may bring about the contamination of water, plants as well as air. Not only do human activities result in air pollution, but some natural disasters create serious atmospheric issues. One of these natural disasters is a volcanic eruption. The significant reason for pollution is globalization. There can be various air pollutants. Some of them are shown below.

- Carbon Monoxide (CO) is a toxic air pollutant.

- Nitrogen Dioxide (NO2) undefined

- $\quad$ Sulfur Dioxide (SO2)

- $\quad$ Ozone (O3)

There are many obstacles to low-cost, compact, and reliable air quality monitoring. Although the field is ripe for innovation, a thorough understanding of the current state-of-the-art (as well as its limiting factors) is needed before moving forward.

Machine learning allows you to create algorithms that learn and evolve as you provide more data. Sensor data has been subjected to these techniques in several ways. The number of people in a closed space can be predicted using changes in distributed sensor readings (temperature, humidity, light, and pressure), or soil moisture can be predicted using remote sensing techniques (i.e., vegetation index and light backscatter). To verify performance, these examples typically use supervised learning approaches with some form of cross-validation. Although each has its own core algorithm (and there is room to test and apply all of them to the air quality space), the logistic regression is worth noting. Engineering failure of products or structures is often predicted using logistic regression. There are multiple use cases present in Smart City, such as environmental monitoring, water distribution, urban security, and waste management. The importance of the Smart City has been spread all over because it provides the solutions and resolves people's living problems that people face these days. The cities' safety ideas, traffic congestion problems, pollution, and reducing noise pollution have been fixed in the Smart City with the help of IoT solutions.

Air pollution is regarded as one of the world's most serious health issues. It can be made by burning fossil fuels, wood, and other similar materials. It can also be made from the toxic gases constantly released into the atmosphere by different industries or factories. It causes severe illnesses such as cancer and lungs disorders, among other things. When there is not a good control system in place, air pollution increases. There is a strong need to implement a device that can detect all the irregular conditions associated with air pollution. The gathered information must then be forwarded to the pollution control department. This study focuses on the design and implementation of a cost-effective air pollution monitoring system using IoT and machine learning algorithms.

\section{LITERATURE REVIEW}

This section provides a detailed discussion on the literature survey of the systems used for the monitoring as well as control of air pollution. The techniques that are being used earlier for the reduction of air pollution will be provided in this section. The periodic modification of these techniques will also be part of this discussion. Moreover, a brief overview of the proposed technique will also be presented in this section of the document.

Rezk et al. presented research which was based on three different algorithms. These algorithms were totally based on machine learning. They were used to observe the weather forecast for one step and multiple steps in order to monitor the concentrations of nitrogen dioxide, sulfur dioxide and ozone. These machine learning algorithms were based on artificial neural networks and the M5P model. He used two different types of modelling as shown below.

- Univariate modelling

- Multivariate modelling

He found that the results obtained from implementation of multivariate modelling with the M5P concept were quite better in comparison to the other technique [1]. In 2017, Jorge et al presented a research in which various sensors were used to collect information. Whereas the management was supposed to act as a mediator for the retrieved and delivered information. He predicted that machine learning algorithms could be used for predicting future atmospheric conditions to deliver a precise set of information for quick observations [2]. Liu Xianpeng presented internet of things-based air pollution monitoring system in Institute of Electrical and Electronics Engineering (IEEE) in 2015. A huge data was provided in this research work. This data was obtained from the network of front-end sensors. It was based on analysis of bog data in the application layer. It was proved to be an effect as well as efficient concept for good decision making [3]. With some further modifications, algorithm can be improved by increasing the number of the input layers.

In 2015, an effective system was presented for the improvement of prediction of air pollution using different machine learning algorithms[5-8]. It was presented at an IEEE conference. He suggested that there is a strong relation between air pollution and the air quality index. This concept was evaluated using machine learning algorithms [4]. He found that the best possible outcomes can be obtained by implementing this idea in different groups. This was possible while using real time sensing modules. Another research work on wireless air pollution monitoring in real time, was presented by Diego Carrera. He presented cheaper and wireless monitoring system that were purely based on multi-layer models [5]. Various agile methodologies were used as given below. 
The wireless sensors-based air pollution monitoring system was introduced by Depak Mehetre and Shwetal Raipure. It was based in metropolitan cities. The AVR at mega 32 microcontroller was used in this study. The data from different sensors, e.g., temperature sensor, humidity sensor, smoke sensor, was collected [6]. The result showed that the Quality of Service (QoS) was greatly increased through this network. Shweta Taneja and Nidhi Sharma presented a system for the prediction of various trends in air pollution. They used data mining technique to get the desired results [7]. The data mining tool used by them was WEKA for future prediction with two algorithms as given below.

- Multi-layer perception

\section{- Linear progression}

For the weather forecasting of urban areas, a machine learning approach was used by Yves Rybarczyk and Rasa Zalakevi [8-11]. They used a decision tree algorithm for predicting air pollution with the help of 2223 data sheet.

An IoT based environment monitoring system was introduced by Jalpa Shah and Biswajit Mishra in 2016. They specifically focused on the measurement of carbon dioxide, temperature, humidity, and other similar parameters [9]. The smart environment monitoring system on a small scale was implemented by Dr. Sumithra and Karthika. They used the internet for effective communication purposes. They monitored the quality of water, soil as well as atmospheric conditions with big data analytics and cloud storage [10]. In the last decade, lots of research work has been carried out on monitoring air pollution. This started when the World Health Organization (WHO) published a health report which said that a high number of deaths have occurred due to the polluted air in the environment [11]. Many research scientists have started implementing statistical techniques as well as machine learning algorithms. Another classic work is presented in [12Air pollution can easily be detected via GPRS based monitoring system [13]. To have an idea about the quality of air in cities, the Wireless Sensor Network (WSN) was introduced [14]. Another research work presented dynamically monitoring of air pollution [15-18]. Air pollution has been increasing continuously and will increase if the proper iterative processes are not considered. The whole world could face extreme weather and atmospheric conditions if this alarming challenge is not properly resolved. There are various types of pollution that cause severe health issues all across the globe. Some major types are listed below.

- Plastic pollution

- Noise pollution

- Air pollution

- Water pollution

- Contamination of soil
We must focus on the solution to these problems to save living beings from the harmful environment in our surroundings. The 3 step machine learning algorithms were implemented by Shaban and Rezk for the development of precise models for weather forecasting [16]. There is a capacity to improve this concept soon as well [17].

\section{METHODOLOGY}

The Proposed model of the system is as follows. Figure 3 shows how the whole system will work. The block diagram of the system is showing that for a particular area selected how will it work. The device will be set up to take the environmental data and there will be a base standard value. The device will collect data and based on the set values it will show the output.

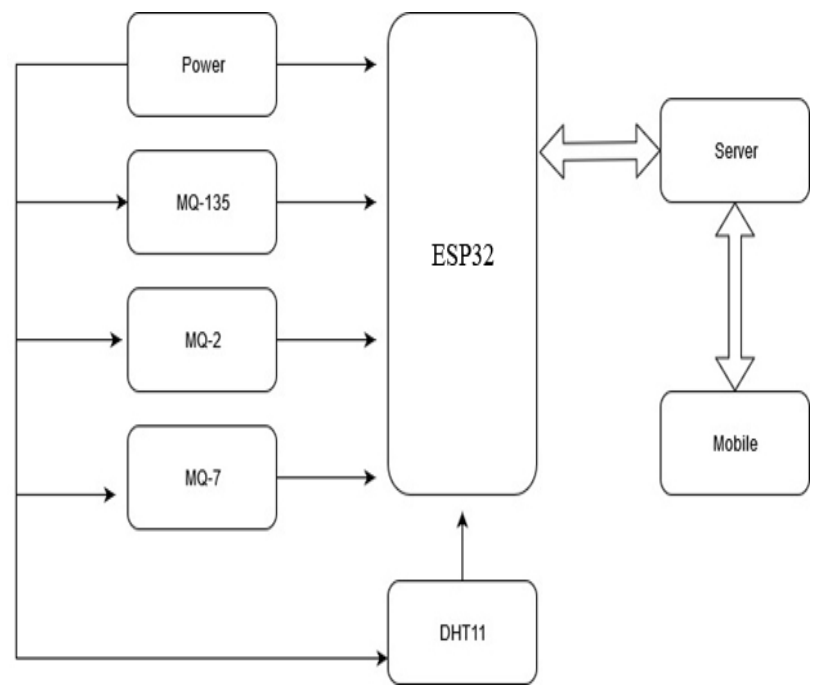

Figure 3.1: Block diagram for proposed model of the system

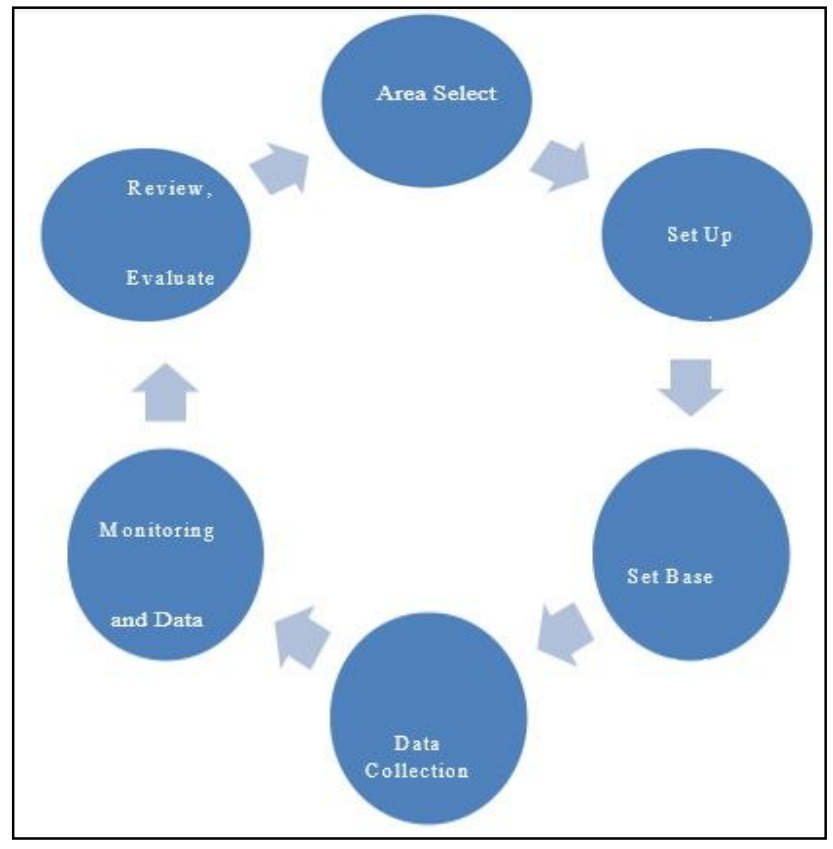

Figure 3.2: Proposed model of the system 


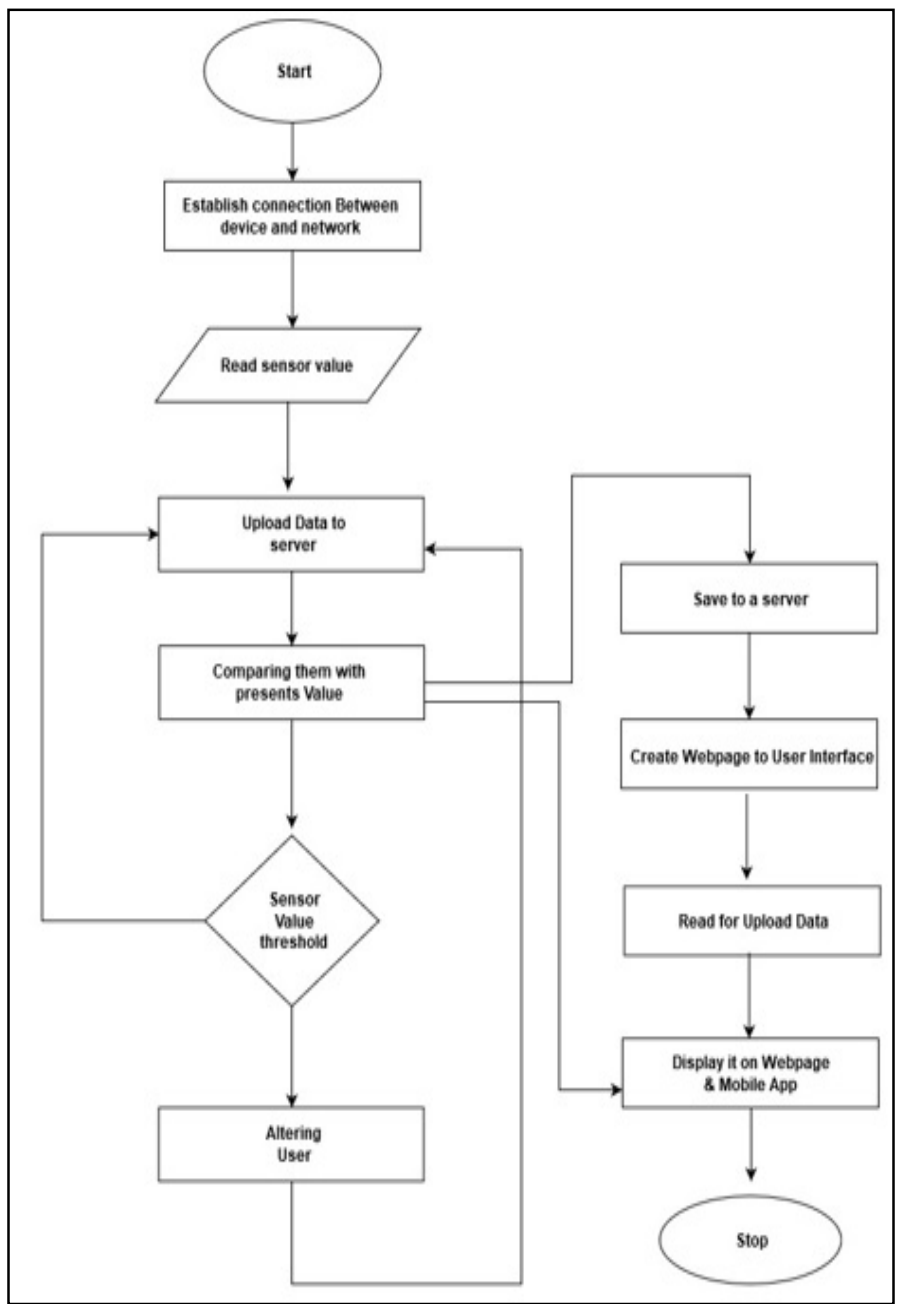

Figure 3.3: Flow chart for the proposed system

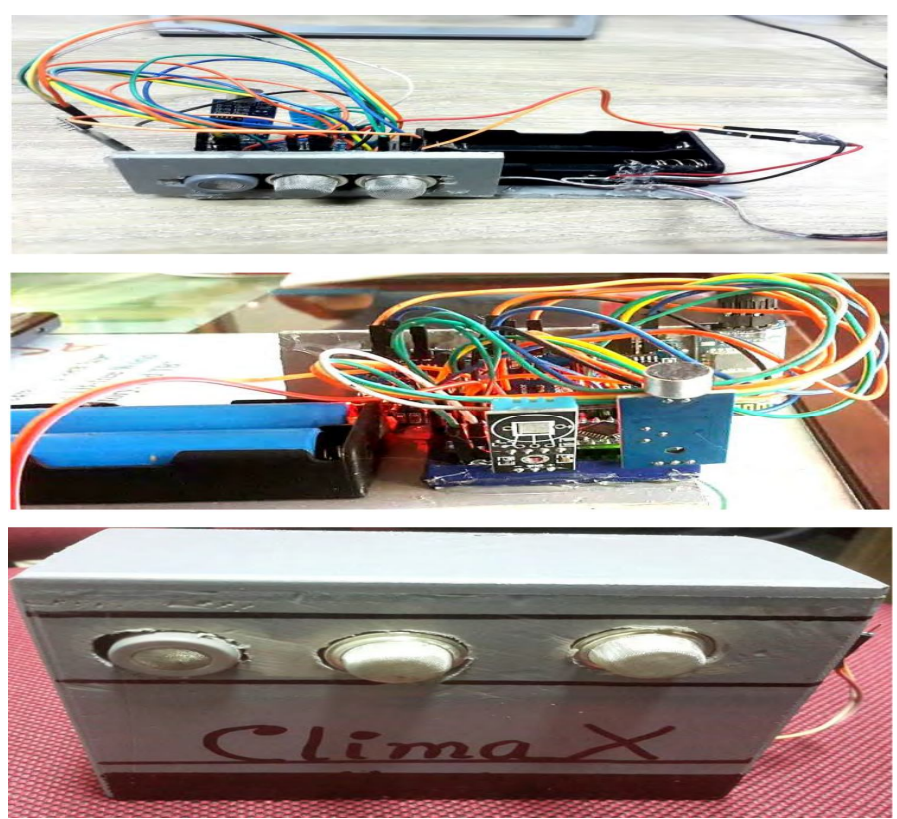

Figure 3.4: Proposed Model in Real Life

\section{IMPLEMENTATION \& ISCUSSIONS}

The goal of an intelligent air pollution monitoring system for smart cities using IoT and machine learning is to develop a high-quality, affordable, and portable air quality monitor.

- Measures several pollutants,

- Measures ambient conditions like temperature, humidity, and light level,

- Connects to a smartphone application that can display results, can send timestamp and geotagged data to the cloud, and can receive and display a prediction of measurement certainty based on machine learning applied to the data in the cloud.

\subsection{MACHINE LEARNING VALIDATION}

Sensor technology- especially in the air quality space- is getting cheaper and more reliable. For the first time, well-respected sensors are starting to appear in the $\$ 100$ range.

\subsection{AIR QUALITY INDEX (AQI) AND ELEMENTAL SAFETY LEVELS}

The air quality index is one of the most relevant parameters that every government uses to warn citizens about the amount of hazardous chemicals and gases in the air. This parameter can also be used to predict the weather in the future. The air pollution index and the air quality index are directly proportional. Air pollution would be higher if the air quality level is higher, and vice versa. The air quality index varies according to the various levels of air quality in different countries. Many elements in the air become toxic and hazardous to humans as their numbers increase. $\mathrm{CO} 2, \mathrm{CO}$, LPG, and CH4 are the four elements we've considered for our project. They have the potential to do serious harm to humans if their numbers are greatly increased. Here are some examples of gas safety standards and AQI: The toxicity level of $\mathrm{CO} 2$ is shown in this table. We can see that it is acceptable and not harmful below 1000ppm, but when it exceeds 2000ppm, it becomes dangerous to humans, and when it exceeds 5000ppm, it can cause severe health problems such as permanent brain damage, coma, and even death. The toxicity levels of $\mathrm{CO}$ in the air, as well as their danger limits, are shown in this table. CO is a highly hazardous gas for humans. We can see that even 9ppm can cause serious harm to a healthy person. The higher the toxicity level, the more likely you are to die. People will die in 2-3 hours if it is above 35ppm and close to $800 \mathrm{ppm}$, and if it reaches $800 \mathrm{ppm}$, it becomes so dangerous that people will die in 1-3 minutes. 


\subsection{HEALTH INDEX FOR AIR QUALITY (AQHI)}

The risks associated to the health of living beings can be categorized in terms of their severity on a scale having values ranging from " 1 " to " 10 ". " 1 " being the lowest danger whereas the "10th" value depicts that there is a lot of polluted air within the particular area.

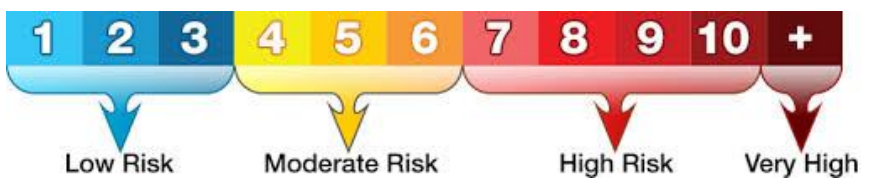

Figure 4.1: Air Quality Health Index Scale

The detailed sale along with the severity of pollution in the air is shown in the Figure 4.1 depicts the health of the air quality and its risk on a scale of one to ten. It is divided into four sections: extremely high, extremely high, extremely high, extremely high, extremely high, extremely high, extremely high, extremely high, extremely high, extremely high, extremely high, extremely high, extremely high, extremely high, extremely high This scale detects the level of air pollution and indicates the danger. When the modified data is compared to the baseline data, the outcome will be shown on this scale. If the compared data is between 1-2, it indicates that the health risk is low and indicates green; if it rises to 4-6, it indicates that air pollution is considered harmful to humans and that we should take immediate action. If it reaches 7 , the affected area is extremely dangerous to humans, and immediate action is required.

\subsection{MECHANICS OF AIR QUALITY INDEX}

The separate value is assigned to every pollutant. The finalized value of air quality index is usually the greatest of the 6 values of the pollutant. There are two different standards of calculating final value of air quality index as given below.

- Per hour

- Per 24 hours

The level of concentrations associated to the pollutants can also be observed and calculated.

If the first way of measuring final value of AQI is followed i.e., updates are required on hourly basis. Then concentrations of carbon monoxide, nitrogen dioxide and sulfur dioxide are required to be recorded every 24 hours. The concentration of ozone is usually recorded on hourly basis whereas its Moving Average (MA) is evaluated after every eight hours. If there is a need to calculate AQI value based on per 24 hours, concentrations of sulfur dioxide, nitrogen dioxide, carbon monoxide, PM2.5 and PM10 are recorded every twenty-four hours thereby evaluating the maximum concentration of ozone. Like the final value of air quality index, the value associate to every pollutant is also non-linear.

\section{Example:}

Two different values of air quality index are calculated as 150 and 300 respectively. It does not mean at all that the AQI-300 is twice as harmful as AQI-150. In simple words, it can be said that this example doesn't depict that AQI-300 has twice air pollution in comparison to AQI-150. Air quality index mechanics are provided in detail in Figure 4.2

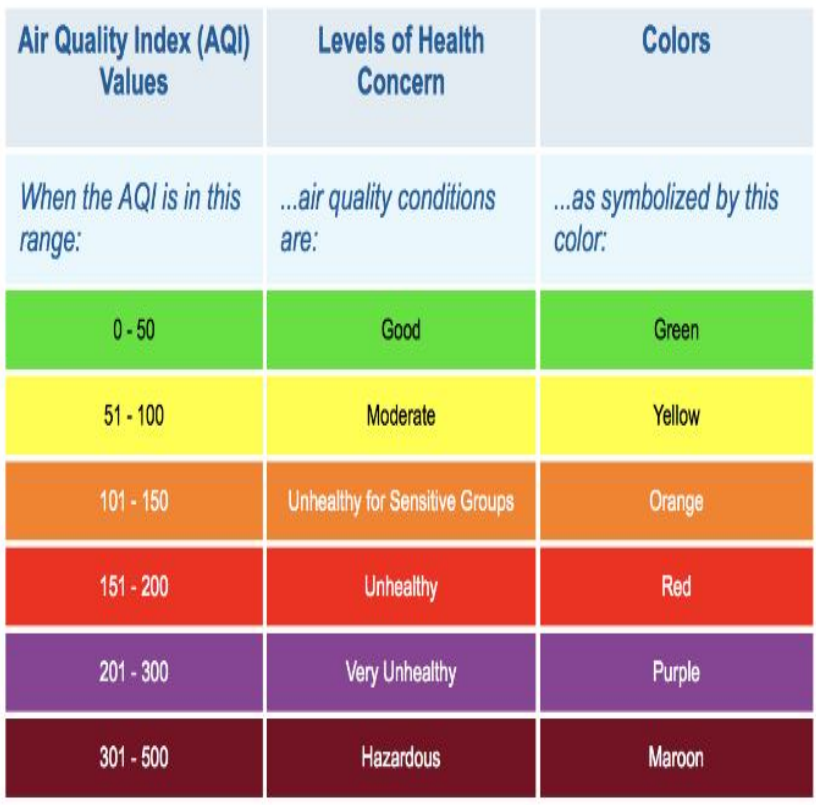

Figure 4.2: Mechanics of Air Quality Index

\subsection{BASE STANDARD SETTING}

In order to assess the state of our country's climate, we used India's AQI group as the system's baseline. Since India and our country have similar environmental conditions and we lack an accurate $A Q I$, their $A Q I$ category is the best fit for us to use as a baseline for our framework to define the range of pollution and condition and take appropriate measures to improve it in the future. India's AQI group is as follows: When the AQI range is between 0 and 50, the data is fine and is shown in pure green color; when the AQI range is 51 to 100 , the data is satisfactory and is shown in greenish color. After that, if the data range is 101-200, the aria is moderately polluted; after that, if the range reaches 201, the region has become severely polluted; and finally, if the data range is $301-400$, the AQI category becomes very low, and the area is extremely polluted and dangerous to humans. The AQI spectrum and associated health impacts are shown in this table. That is to say, the AQI table depicts the effect of pollution on our wellbeing. The impact is marginal when the AQI is fine. It can cause mild breathing irritation to sensitive people when it is satisfactory. To children and older adults, a moderately polluted range suggests difficulty in breathing, lung disease, asthma, and heart disease. For people who have been exposed for a long time, poor means respiratory problems and heart failure. Very low suggests lung and heart 
disease as well as respiratory illness. Finally, severe denotes that it is extremely unhealthy, i.e., it has the potential to cause health cancer.

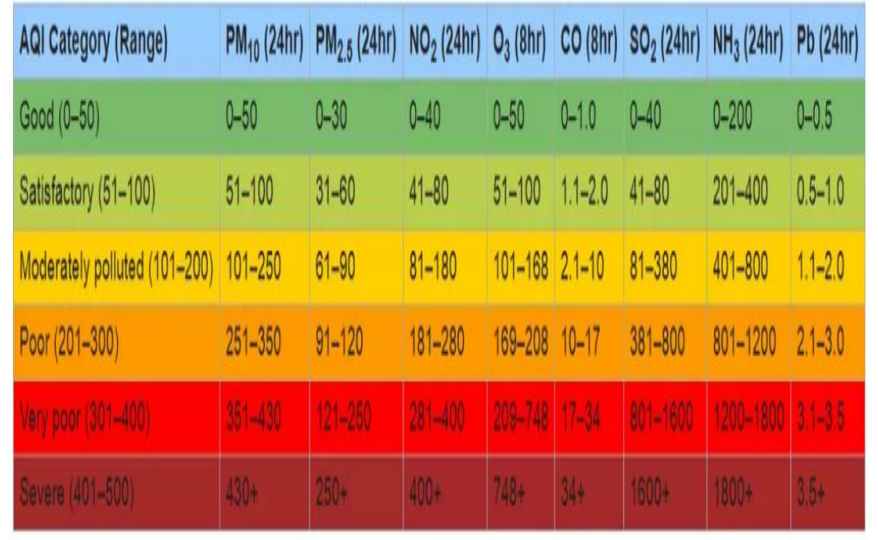

Figure 4.3: AQI Category, Pollutants and Health Breakpoints

\subsubsection{DATA COMPARISON}

Using this device, we have taken data of temperature and humidity from around the country. To check how accurate our data are we have taken help from a trusted website. We have compared our data with the data of this website and found the result below:

\begin{tabular}{|c|c|c|c|c|c|c|c|c|}
\hline SN & Time & Teperature & Humidity & $\mathrm{CO} 2$ & 200 & H2 & LPG & Sound \\
\hline 1 & $2018-06-11 \quad 11: 29-41$ & 33.00 & 68 & 641 & 15 & 287 & 540 & 0 \\
\hline 2 & 2018-06-11 11:29-41 & 33.00 & 68 & 641 & 15 & 287 & 540 & 0 \\
\hline 3 & $2018-06-1111: 29-40$ & 33.00 & 68 & 641 & 15 & 287 & 540 & 0 \\
\hline 4 & $2018-06-1111-2940$ & 33.00 & 68 & 641 & 15 & 287 & 540 & 0 \\
\hline 5 & $2018-06-1111: 29,39$ & 33.00 & 68 & 641 & 15 & 287 & 540 & 0 \\
\hline 6 & $2018-06-1111: 2939$ & 33.00 & 68 & 641 & 15 & 287 & 540 & 0 \\
\hline 7 & $2018-06-11 \quad 11 ; 29-38$ & 3300 & 68 & 641 & 15 & 287 & 540 & 0 \\
\hline 8 & $2018-06-1111: 29: 38$ & 33,00 & 68 & 641 & 15 & 287 & 7540 & 0 \\
\hline 9 & 2018-06-11 11:29:37 & 33.00 & 68 & 641 & 15 & 287 & 540 & 0 \\
\hline 10 & $2018-06-1111: 29: 37$ & 33.00 & 68 & 641 & 15 & 287 & 540 & 0 \\
\hline 11 & $2018-06-111127.55$ & 33.00 & 68 & 648 & 14 & 290 & 557 & 0 \\
\hline 12 & $2018-06-1111: 27 \cdot 54$ & 33.00 & 68 & 648 & 14 & 290 & 557 & 0 \\
\hline 13 & $2018-06-1111: 27: 53$ & 33.00 & 68 & 648 & $\sqrt{14}$ & 290 & 557 & 0 \\
\hline 14 & $2018-06-1111: 27-53$ & 3300 & 68 & 648 & 14 & 290 & 557 & 0 \\
\hline 15 & $2018-06-1111: 27-52$ & 33.00 & 68 & 648 & 14 & 290 & 557 & 0 \\
\hline 16 & $2018-06-111127.52$ & 3300 & 68 & 648 & 14 & 290 & 557 & 0 \\
\hline 17 & $2018-06-111127+49$ & 32.00 & 71 & 652 & 19 & 610 & $5 \sqrt[575]{2}$ & 0 \\
\hline 18 & $2018-06-1111: 27-48$ & $\$ 3300$ & 68 & 645 & 14 & 290 & 557 & $\sqrt{0}$ \\
\hline 19 & $2018-06-11.11: 27-48$ & 3200 & 71 & 652 & 19 & 610 & $5 \sqrt[575]{5}$ & 0 \\
\hline 20 & $2018-06-11 \quad 11: 27: 48$ & 3300 & 68 & 648 & 14 & 290 & 537 & 0 \\
\hline 21 & 2018-06-11 11:27:47 & 3200 & 71 & 652 & 19 & 610 & 575 & 0 \\
\hline 22 & $2018-06-1111: 27: 47$ & 33.00 & 68 & 648 & 14 & 290 & 557 & 0 \\
\hline 23 & $2018-06-1111-27+47$ & 3200 & 71 & 652 & 19 & 610 & 575 & 0 \\
\hline 24 & $2018.06-1111: 27,46$ & 33.00 & 68 & 648 & 14 & 290 & 557 & 0 \\
\hline 25 & $2018-06 \cdot 1111: 27 \cdot 46$ & 32.00 & 71 & 652 & 19 & $\sqrt{610}$ & 575 & 0 \\
\hline
\end{tabular}

Table 4.1: Data Comparison
This chart represents the data that are collected and saved to the server and these data will be calculated through mean and standard deviation and we will the result in graph like below:

TEMPERATURE STATS

\section{Temperature \& Humidity}

Last week analysis

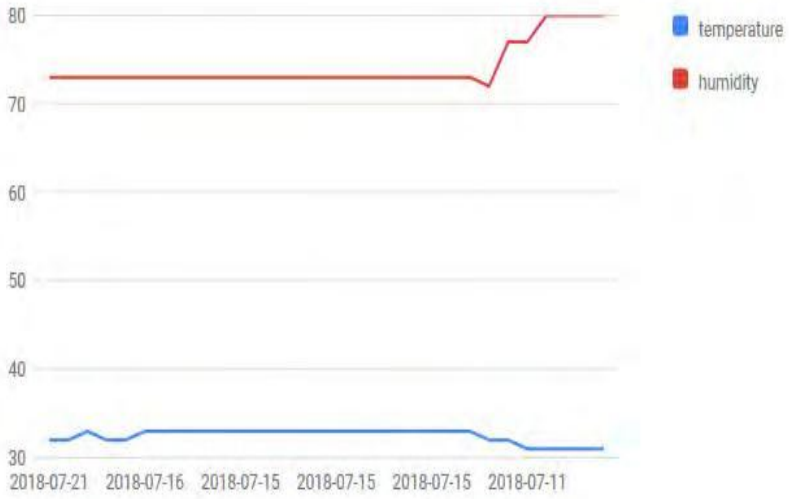

Date

Figure 4.4: Temperature and humidity graph

\subsection{WEB PROGRAMMING}

Two key portions of internet programming are Front-End and Back-End. Front end programming is about design portion of a web page where all the design works, and layout of the page contains properly. Front end is all about user interface and what are visible to the user. In the front page here actually appears the content design of the page that shows how the webpage would look like properly.

\subsection{USER APPLICATION}

After sending all the values and measurements to the server, the application will show the Android app UI.

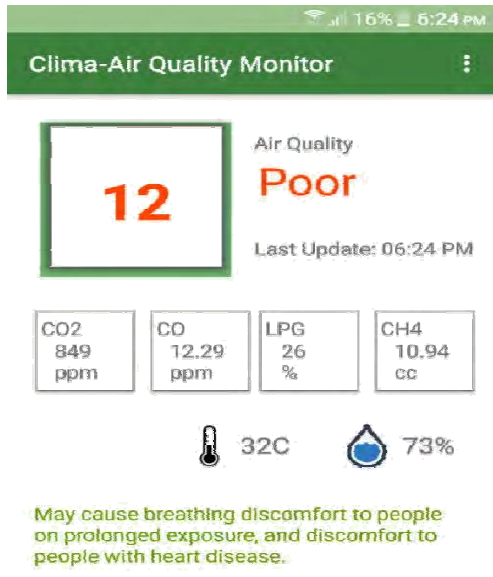
people with heart disease.

Figure 4.5: Android app UI 
There will be 3 colors to differentiate the values which were sent by the device and these colors are green, yellow and red. After calculating the values, if the values are reasonable and match with the standard base value, then it will show the green color.

If the values are at a moderate level, it will show the users yellow color and when the values are too much higher than the standard base, that means it will be too risky and it will show red color to the users. At that time, the app users will receive a message from the server and it will indicate to the users to take necessary steps to bring the values down. End users will see the real time graphs and all other charts related to the values and it will show the charts which will be found after a full measurement of all the values. Here, we can see the UI of our android app which will be provided to the users. In this user interface there are several parts. On the upper hand, it has shown that the air quality is "poor". It means that the condition of the air is not good enough and it's unsafe. In the middle there are the names of the gases and beside them their real time reading. The temperature sign is shown in Celsius form in the lower part, along with the humidity percentage. Most importantly, on the basis of the measurements, the app will give some comments which will give the idea about the problems which are going to be faced by people because of the air conditions.

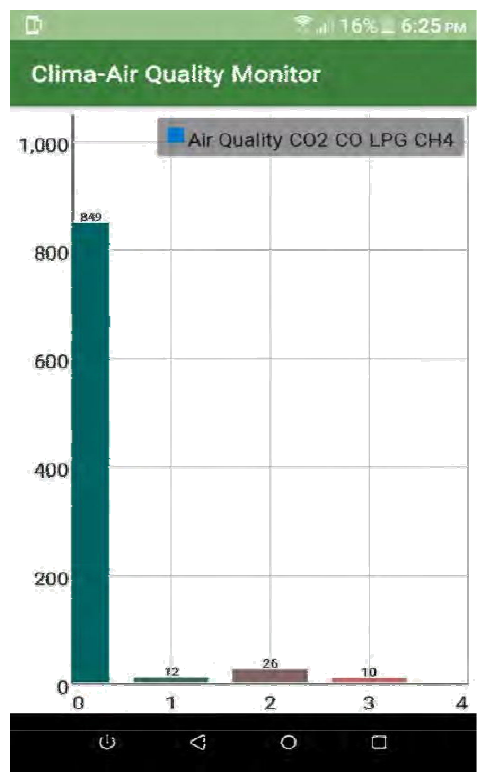

Figure 4.6: Air quality of $\mathrm{CO} 2, \mathrm{CO}, \mathrm{LPG}$, and $\mathrm{CH} 4$

Here, we can see the UI of our android app which will give us the idea about the air quality of $\mathrm{CO} 2, \mathrm{CO}, \mathrm{LPG}$, and $\mathrm{CH} 4$. The first column shows the real-time $\mathrm{CO} 2$ reading, which is $849 \mathrm{ppm}$; the second column shows the real-time CO reading, which is $12 \mathrm{ppm}$; the third column shows the real-time LPG reading, which is $26 \%$; and the fourth column shows the real-time $\mathrm{CH} 4$ reading, which is $10 \mathrm{cc}$.

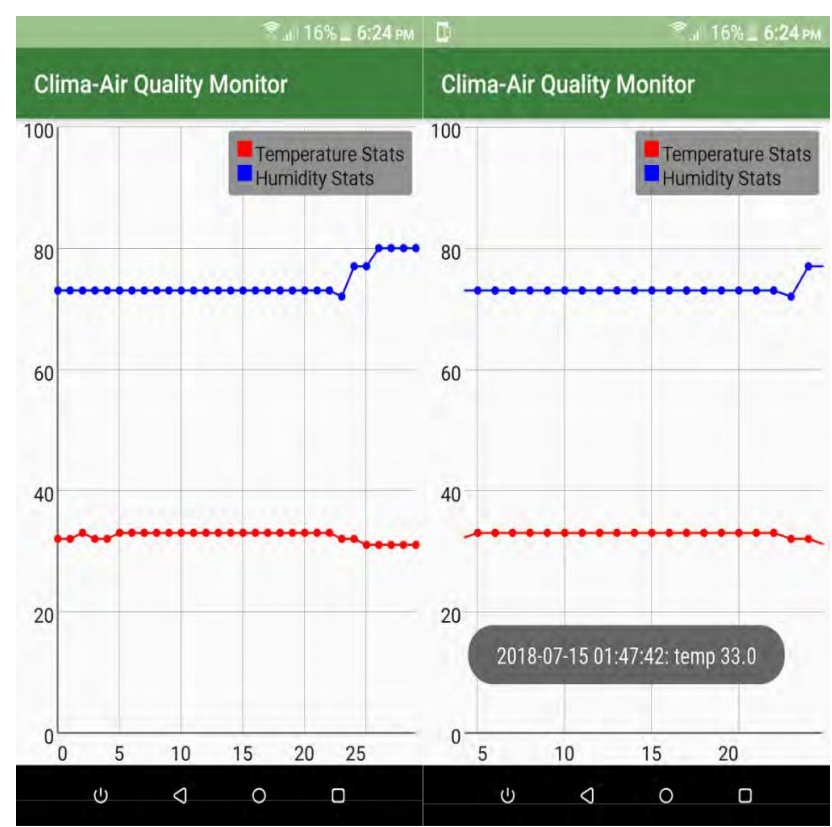

Figure 4.7: Real time graph of Temperature and Humidity

Here, we can see the real time graph of Temperature and Humidity. The Red line is representing the temperature states of the real time and the Blue line is representing the humidity states of real time. And the line is about continues reading, and the $\operatorname{dot}($.$) in between of the lines are representing a$ particular time's reading. When we click on a dot it will show us the actual reading of that time.

\section{EXPERIMENTAL RESULT ANALYSIS}

We have taken the last 10 days of data from 11-20th July 2020 and stored them in the server. After that we have taken two trustedwebsiteswww.accuweather.comwww.timeanddate.co $\mathrm{m}$ and https://www.airvisual.com/for comparing our data of temperature and humidity, respectively. We found the below result for each table:

\section{For Temperature:}

\section{Mean of System data:}

$T s=\frac{250}{10}=35^{\circ} \mathrm{C}[\mathrm{Ts}=$ System temperature $]$

\section{Mean of Website data:}

$T w=\frac{371}{10}=37.1[\mathrm{Tw}=$ Website temperature $]$

\section{Percentage of error:}

$E=\frac{3,1-35}{37} \times 100=5.66 \%$

\section{Percentage of accuracy:}

$A=(100-5.66) \%=94.34 \%$ 


\section{For Humidity:}

\section{Mean of System data:}

$\mathrm{H} s=\frac{752}{10}=75.2[\mathrm{Hs}=$ System humidity $]$

Mean of Website data:

$H w=\frac{764}{10}=76.4[\mathrm{Hw}=$ Website humidity $]$

Percentage of error:

$E=\frac{76.4-75.2}{76.4} \times 100=1.57 \%$

Percentage of accuracy:

$A=(100-1.57) \%=98.43 \%$

For Air Quality Index:

Mean of System data:

As $=\frac{1722}{10}=173.2[\mathrm{Hs}=$ System Air Quality Index $]$

Mean of Website data:

A $w=\frac{1992}{10}=189.2$ [ Hw = Website Air Quality Index]

Percentage of error:

$E=\frac{199.2-173.2}{199.2} \times 100=8.4 \%$

Percentage of accuracy:

$A=(100-8.4) \%=91.6 \%$

\subsection{ANALYSIS}

Here, we have seen that our device can take almost accurate results of temperature and humidity. Though there is a margin of error and it is $5.66 \%$ for temperature and $1.57 \%$ for humidity. So, we can say that our device is working perfectly. There are some problems for which the data are not exact as the found on the website. The sensors are cheap and fragile, and they intend to damage quicker. There range of taking data's is also low and limited and that is why we couldn't take more and accurate results. Our device working rate is very good and it has a very high accuracy. If we use more expensive sensors, our result would have been more accurate and perfect.

\subsection{DATA CHART OF THE SENSORS}

Here is the chart of the sensors that is used to take the readings of a certain place. In this chart we have seen that $\mathrm{CO} 2$ result is in between 350-1000 ppm, which states that concentrations typical of occupied indoor spaces with good air exchange. It means that $\mathrm{CO} 2$ level, is good for human. The chart shows the result of the level of CO below $35 \mathrm{ppm}$, which is in tolerable range but if anyone stays in this area with prolonged exposure it may cause them heart disease. The other sensor MQ 7 gives us the result in the range of 540-567 ppm which is in the range of normal standard value. The MQ2 sensor delivers the result within the range of 540-570 which is also states in normal condition.

\begin{tabular}{|c|c|c|c|}
\hline $\mathrm{CO}_{2}(\mathrm{ppm})$ & $\mathrm{CO}(\mathrm{ppm})$ & $\mathrm{H}_{2}(\mathrm{ppm})$ & LPG (ppm) \\
\hline 641 & 15 & 287 & 540 \\
\hline 643 & 15 & 287 & 542 \\
\hline 641 & 13 & 287 & 537 \\
\hline 641 & 11 & 287 & 545 \\
\hline 641 & 15 & 287 & 547 \\
\hline 647 & 15 & 287 & 547 \\
\hline 648 & 16 & 287 & 547 \\
\hline 641 & 15 & 287 & 545 \\
\hline 641 & 15 & 287 & 542 \\
\hline 654 & 15 & 287 & 542 \\
\hline 648 & 14 & 290 & 541 \\
\hline 648 & 15 & 290 & 543 \\
\hline 648 & 14 & 288 & 537 \\
\hline 648 & 14 & 290 & 545 \\
\hline 648 & 14 & 290 & 547 \\
\hline 648 & 14 & 310 & 547 \\
\hline 652 & 19 & 290 & 548 \\
\hline 648 & 14 & 310 & 552 \\
\hline 652 & 19 & 280 & 552 \\
\hline 646 & 15 & 285 & 557 \\
\hline & & & \\
\hline
\end{tabular}

Table 5.1: Data Chart of Sensors

\section{CONCLUSIONS}

This research presents a smart way to track the atmosphere, air, and sound pollution using a low-cost, reliable, and embedded device. The roles of various sensors and how they operate were discussed in the proposed architecture. They are also discussed in terms of how they operate, their features, their best uses, and their data collection methods and comparisons to standard base data. The noise and air pollution monitoring system was put to the test in order to keep track of gas levels in various parts of the world. The sensor parameters were also sent to the data server. Our project device demonstrated that it is effective and inexpensive, and that with some well-functioning sensors, it can truly be a reliable one for everyone. Its data will be a key to taking some necessary steps for the betterment of society, as it will assist in identifying the affected area so that we can take early steps to reduce damages for future generations.

\section{ACKNOWLEDGEMENT}

Authors are very thankful to Reviewers for valuable suggestions which enhanced the quality of manuscript.

\section{REFERENCES}

1. Jurik, A.D. and Weaver, A.C., 2008. Remote medical monitoring. Computer, 41(4), pp.96-99.

2. Shaban, K.B., Kadri, A. and Rezk, E., 2016. Urban air pollution monitoring system with forecasting models. IEEE Sensors Journal, 16(8), pp.2598-2606.

3. Gómez, J.E., Marcillo, F.R., Triana, F.L., Gallo, V.T., Oviedo, B.W. and Hernández, V.L., 2017. IoT for environmental variables in urban areas. Procedia computer science, 109, pp.67-74.

4. Ayele, T.W. and Mehta, R., 2018, April. Air pollution monitoring and prediction using IoT. In 2018 second 
international conference on inventive communication and computational technologies (ICICCT) (pp. 1741-1745). IEEE.

5. Xi, X., Wei, Z., Xiaoguang, R., Yijie, W., Xinxin, B., Wenjun, Y. and Jin, D., 2015, November. A comprehensive evaluation of air pollution prediction improvement by a machine learning method. In 2015 IEEE international conference on service operations and logistics, and informatics (SOLI) (pp. 176-181). IEEE.

6. Fuertes, W., Carrera, D., Villacís, C., Toulkeridis, T., Galárraga, F., Torres, E. and Aules, H., 2015, October. Distributed system as internet of things for a new low-cost, air pollution wireless monitoring on real time. In 2015 IEEE/ACM 19th International Symposium on Distributed Simulation and Real Time Applications (DS-RT) (pp. 58-67). IEEE.

7. Raipure, S. and Mehetre, D., 2015, April. Wireless sensor network based pollution monitoring system in metropolitan cities. In 2015 International Conference on Communications and Signal Processing (ICCSP) (pp. 1835-1838). IEEE.

8. EPA, U., 2001. United States Environmental Protection Agency. Quality Assurance Guidance Document-Model Quality Assurance Project Plan for the PM Ambient Air, 2.

9. Rybarczyk, Y. and Zalakeviciute, R., 2016, October. Machine learning approach to forecasting urban pollution. In 2016 IEEE Ecuador Technical Chapters Meeting (ETCM) (pp. 1-6). IEEE.

10. Shah, J. and Mishra, B., 2016, January. IoT enabled environmental monitoring system for smart cities. In 2016 international conference on internet of things and applications (IOTA) (pp. 383-388). IEEE.

11. Ayele, T.W. and Mehta, R., 2018, April. Air pollution monitoring and prediction using IoT. In 2018 second international conference on inventive communication and computational technologies (ICICCT) (pp. 1741-1745). IEEE.

12. World Health Organization, 2014. Air quality deteriorating in many of the world's cities. last modified.

13. Yi, J. and Prybutok, V.R., 1996. A neural network model forecasting for prediction of daily maximum ozone concentration in an industrialized urban area. Environmental pollution, 92(3), pp.349-357.

14. Al-Ali, A.R., Zualkernan, I. and Aloul, F., 2010. A mobile GPRS-sensors array for air pollution monitoring. IEEE Sensors Journal, 10(10), pp.1666-1671.

15. Raipure, S. and Mehetre, D., 2015, April. Wireless sensor network based pollution monitoring system in metropolitan cities. In 2015 International Conference on Communications and Signal Processing (ICCSP) (pp. 1835-1838). IEEE.

16. Shaban, K.B., Kadri, A. and Rezk, E., 2016. Urban air pollution monitoring system with forecasting models. IEEE Sensors Journal, 16(8), pp.2598-2606.
17. Xi, X., Wei, Z., Xiaoguang, R., Yijie, W., Xinxin, B., Wenjun, Y. and Jin, D., 2015, November. A comprehensive evaluation of air pollution prediction improvement by a machine learning method. In 2015 IEEE international conference on service operations and logistics, and informatics (SOLI) (pp. 176-181). IEEE.

18. Taneja, S., Sharma, N., Oberoi, K. and Navoria, Y., 2016, August. Predicting trends in air pollution in Delhi using data mining. In 2016 1st India international conference on information processing (IICIP) (pp. 1-6). IEEE. 